\title{
Health-related factors for work participation in persons with spinal cord injury in Finland
}

\section{Eskola, Kaarina L}

$2022-10$

Eskola , K L , Koskinen , E , Anttila , H , Tallqvist , S , Bergman , P H , Kallinen , M , Hämäläinen , H , Kauppila , A-M , Täckman , A, Vainionpää , A , Arokoski , J , Rajavaara , M \& Hiekkala , S 2022 , ' Health-related factors for work participation in persons with spinal cord injury in Finland ' , Journal of Rehabilitation Medicine , vol. 54 . https://doi.org/10.2340/jrm.v53.59

http://hdl.handle.net/10138/340189

https://doi.org/10.2340/jrm.v53.59

cc_by_nc

publishedVersion

Downloaded from Helda, University of Helsinki institutional repository.

This is an electronic reprint of the original article.

This reprint may differ from the original in pagination and typographic detail.

Please cite the original version. 


\section{HEALTH-RELATED FACTORS FOR WORK PARTICIPATION IN PERSONS WITH SPINAL CORD INJ URY IN FINLAND}

Kaarina ESKOLA, MSc ${ }^{1,2}$, Eerika KOSKINEN, MD, PhD ${ }^{3}$, Heidi ANTTILA, PhD ${ }^{4}$, Susanna TALLQVIST, MSc ${ }^{5}$, Paula BERGMAN, MSC ${ }^{6}$, Mauri KALLINEN, MD, PhD ${ }^{7,8}$, Harri HÄMÄLÄINEN, MD, PhD ${ }^{9}$, Anna-Maija KAUPPILA, MD, PhD ${ }^{10}$, Anni TÄCKMAN, BBA ${ }^{11}$, Aki VAINIONPÄÄ, MD, PhD ${ }^{12}$, Jari AROKOSKI, MD, PhD ${ }^{13}$, Marketta RAJAVAARA, PhD ${ }^{14}$ and Sinikka HIEKKALA, PhD ${ }^{15,16}$

From the ${ }^{1}$ Doctoral Programme in Social Sciences, University of Helsinki, Helsinki, ${ }^{2}$ Tampere University Hospital, Department of Rehabilitation and Psychosocial Support, ${ }^{3}$ Tampere University Hospital, Department of Rehabilitation and Psychosocial Support, Tampere, ${ }^{4}$ Finnish Institute for Health and Welfare (THL), Public Health and Welfare Department, Knowledge Management and Co-creation Unit, Helsinki, ${ }^{5}$ University of J yväskylä, Faculty of Sport Sciences J yväskylä, ${ }^{6}$ Biostatistics Unit, University of Helsinki, Helsinki, ${ }^{7}$ Department of Rehabilitation Medicine, Central Finland Health Care District, Central Finland Central Hospital, Jyväskylä, ${ }^{8}$ Center for Life Course Health Research, University of Oulu, Oulu, ${ }^{9} \mathrm{Helsinki}$ University Hospital, Department of I nternal Medicine and Rehabilitation/Spinal Cord I njury Outpatient Clinic, Helsinki, ${ }^{10}$ Oulu University Hospital, Department of Medicine and Rehabilitation Oulu, ${ }^{11}$ The Finnish Association of Spinal Cord I njured Akson, Helsinki, ${ }^{12}$ Seinäjoki Central Hospital, Department of Rehabilitation, Seinäjoki, ${ }^{13} \mathrm{Helsinki}$ University Hospital, Department of Internal Medicine and Rehabilitation/Spinal Cord Injury Outpatient Clinic, ${ }^{14}$ Doctoral Programme in Social Sciences, University of Helsinki, ${ }^{15}$ The Finnish Association of People with Physical Disabilities and ${ }^{16}$ Validia Rehabilitation, Helsinki, Finland

Objective: To explore work participation and the health-related factors affecting work participation among the Finnish Spinal Cord injury (FinSCI) study population ( $n=884$ ).

Methods: A cross-sectional explorative observational study in the FinSCl community survey applying Patient-Reported Outcomes Measurement Information System (PROMIS ${ }^{\circledR}$ ) forms on Social Health and Global Health. Analyses of socio-demographic and injury-related data were performed.

Results: Employment among the study population ( $n=452)$ was $26.5 \%$. Physical, Mental, Social and General Health were better in the employed group compared with work-age persons not working. Logistic regression showed that work participation was related to all health domains, but Physical Health and Ability to Participate in Social Roles and Activities in Social Health were the strongest indicators of likelihood of being at work. Paraplegia and young age were associated with increased likelihood of work participation.

Conclusion: The first national survey among people with spinal cord injury in Finland shows low level of employment. The results suggest that pain, physical function, and ability to participate in social roles should be monitored by health and vocational professionals when assessing a person's likelihood of being in work.

Key words: health; spinal cord injuries; employment.

Accepted Nov 17, 2021; Epub ahead of print Dec 10, 2021

J Rehabil Med 2022; 54: jrm00255

Correspondence address: Kaarina Eskola, Tampere University Hospital, Department of Rehabilitation and Psychosocial Support, PO Box 2000, FIN-33521 Tampere, Finland. E-mail: kaarina.eskola pshp.fi

$S_{\mathrm{s}}^{\mathrm{p}}$ pinal cord injury (SCI) results in immediate, and generally permanent, changes in all aspects of life, including participation in paid work $(1,2)$. Persons

$$
\rho \rho \delta \quad \rho \rho
$$

\section{LAY ABSTRACT}

The data source for this study was the Finnish Spinal Cord Injury Study (FinSCI), which collected extensive information from people with spinal cord injury about their health and employment status. A total of 452 responders from the FinSCl survey were included in the current study. The employment rate in the FinSCl study population was low $(26.5 \%)$ and the majority of those not in work $(73.5 \%)$ were receiving a disability pension. The analysis of health factors showed that all health aspects were better in the employed group compared with the group who were not working. Physical Health, Ability to Participate in Social Roles and Activities, less severe injury, and young age were associated with likelihood of work participation. This study provides up-to-date selfreported data for the spinal cord injury population and health professionals, helping to identify health-related problems that could be barring employment.

status in all domains of physical functioning, role functioning, vitality, and mental health (3).

Employment is an important key indicator of successful rehabilitation and community integration and is an essential component of good health, life satisfaction, and quality of life (QoL) for persons with SCI $(4,5)$. The worldwide mean rate of employment after SCI is approximately $35-38 \%(4,6)$. The overall employment rates range from $10.3 \%$ to $61.4 \%$ (6). In Finland, no statistical source about participation of persons with SCI in the employment market is available to date.

$\rho$

health. Health is generally described using the conceptual framework by the World Health Organization's $\rho$

Disability and Health (ICF), which corresponds to the complexity and many-faceted nature of SCI (7). The ICF is based on an integrative, biopsychosocial model of health, functioning, and disability $(8,9)$. The ICF has become an international standard for describing 
health and functioning, and a large number of health measures have been mapped to this framework (8).

In previous studies, reported characteristics associated with employment after SCI include demographic variables (education, sex, race, marital status), injuryrelated factors (age at injury, level of injury/impairment/functional status, time since injury), employment history (employment at or before injury), transport, psychosocial issues (physical health, life satisfaction, focus of control, motivational level/expectation

$$
\rho \quad \rho \quad \delta \delta
$$

$(2,4)$. Barriers to working appear to be partly healthrelated; they include health problems or too much pain, $\delta$

a suitable job, problems with transport, lack of work experience, education, or training, physical or architectural barriers, discrimination by employers, and loss

$$
\rho \quad \rho \quad \rho
$$

persons injured at a younger age and in those with less severe injuries and higher functional independence (4, 10 ). There is a lack of studies simultaneously covering physical, mental and social aspects of health related to work participation among persons with SCI.

The objective of this study was to explore work $\rho \quad \rho \quad \rho$ tionwide community survey for the SCI population in Finland (FinSCI) (12) and to investigate health-related determinants for work participation across relevant SCI groups based on demographic data, social, mental, and physical health-related factors, as well as SCI characteristics, using the Patient-Reported Outcomes Measurement Information System (PROMIS ${ }^{\circledR}$ ) self-report measures (8). This research offers a broad perspective on participation in work, including Physical, Mental, and Social Health, by using patient-reported measures. Patient-reported outcome measures (PROMs) have gained ground in recent years as the new means for comparative performance assessment (13).

\section{METHODS}

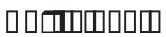

The participants were selected from the data of the FinSCI survey (12), and were patients during the years 2011-18 in Oulu, Tampere, and Helsinki University Hospitals (SCI outpatient clinics). The survey was implemented from February 2019 until the end of July 2019. The response rate to the survey was $49.9 \%$ of the eligible 1,772 participants. FinSCI was approved by the Hospital District of Helsinki and Uusimaa (HUS) Coordinating Ethics Committee (HUS/1776/2017).

The inclusion criteria for FinSCI were: age at least 16 years, permanently living in Finland, non-traumatic or traumatic SCI

$$
\begin{array}{lllllll}
\delta & & \rho & & \rho & & \rho \\
& & \rho & \delta & \rho & \rho &
\end{array}
$$

outpatient clinics responsible for lifelong follow-up care in Finland $\rho \delta \quad \delta \quad \rho \quad \rho \quad \rho \quad-$ sessed based on the International Standards for the Neurological

$$
\rho \delta \rho
$$

$\begin{array}{lllllll}\rho & \rho & \rho & \delta & \delta & \rho\end{array}$

SCI, progressive and new non-traumatic SCI, neurodegenerative disease, multiple sclerosis, amyotrophic lateral sclerosis, GuillainBarré syndrome, and patients living in an institution (12). The protocol of the FinSCI is presented elsewhere (12).

Of the 884 respondent participants in the FinSCI, all working responders and individually determined working-aged persons
$\rho \quad \delta \delta$

\begin{tabular}{|c|c|c|c|c|}
\hline & & Employed & Work aged not at work & $p$-value \\
\hline Variable, n (\%) & $\mathrm{n}$ & $120(26.5)$ & $332(73.5)$ & \multirow{3}{*}{$0.466^{*}$} \\
\hline \multirow[t]{2}{*}{ Gender, n (\%) } & Male & $86(27.6)$ & $226(72.4)$ & \\
\hline & Female & $34(24.3)$ & $106(75.7)$ & \\
\hline \multirow[t]{3}{*}{ Current age, mean (SD) } & & $47.58(11.350)$ & $50.69(11.099)$ & \\
\hline & Minimum & 23 & 20 & \\
\hline & Maximum & 74 & 66 & \\
\hline \multirow[t]{5}{*}{ Family relations, $\mathrm{n}(\%)$} & Living alone & $39(8.6)$ & $123(27.2)$ & \multirow{5}{*}{$0.218^{*}$} \\
\hline & In the household child/children & $7(1.5)$ & $14(3.1)$ & \\
\hline & With spouse, no children & $38(8.4)$ & $112(24.8)$ & \\
\hline & With spouse, in the household child/children & $31(6.9)$ & $58(12.8)$ & \\
\hline & Another form of residence & $5(1.1)$ & $25(5.5)$ & \\
\hline \multirow[t]{2}{*}{ Age group, $\mathrm{n}(\%)$} & $20-53$ years $^{b} 224(49.6)$ & $73(16.2)$ & $151(33.4)$ & \multirow{2}{*}{$0.004 *$} \\
\hline & $54-74$ years $228(50.4)$ & $47(10.4)$ & $181(40.0)$ & \\
\hline \multirow[t]{2}{*}{ Cause of the injury, $\mathrm{n}(\%)$} & Traumatic & $70(15.5)$ & $200(44.2)$ & \multirow{2}{*}{$0.715^{*}$} \\
\hline & Non-traumatic & $50(11.0)$ & $132(29.2)$ & \\
\hline \multirow[t]{2}{*}{ Years since injury, $\mathrm{n}(\%)$} & $1-5$ years & $45(10.0)$ & $123(27.2)$ & \multirow{2}{*}{$0.864 *$} \\
\hline & 16 years & $26(5.8)$ & $74(16.4)$ & \\
\hline \multirow[t]{4}{*}{ Severity of spinal cord injury, n (\%) } & AIS C1-C4 A, B, C & $8(1.8)$ & $44(9.7)$ & \multirow{4}{*}{$0.187^{*}$} \\
\hline & AIS C5-C8 A, B, C & $7(1.5)$ & $24(5.3)$ & \\
\hline & AIS T1-S5 A, B, C & $29(6.4)$ & $83(18.4)$ & \\
\hline & AIS D in all neurological levels & $76(16.8)$ & $181(40.0)$ & \\
\hline
\end{tabular}
${ }_{\rho}{ }^{\delta}{ }^{\delta} \delta \delta^{\rho}$
$\delta \rho \rho$
$\rho \rho \delta$

Table I. Comparison of the working and not at work participants ${ }^{a}$ of the Finnish Spinal Cord Injury (FinSCl) survey $(n=452)$

* Pearson Chi-square. ${ }^{\text {a }}$ Retired people are not included in a sample. ${ }^{\text {b}}$ The youngest respondent was 20 -year-old. AIS: ASIA Impairment Scale. 
were excluded. The sample of work-aged persons not working and working persons were divided into 2 groups according to their employment status.

\section{प्राप्रा}

ICF acted as a framework in a study to capture what matters most to affected persons $(16,17)$. The detailed selection of 43 ICF categories, including the usage of SCI-related ICF Core Sets, is presented in the FinSCI Protocol (12). The outcome measures were selected on the coverage of the chosen ICF categories. PROMIS $^{\circledR}$ was the principal generic instrument in the FinSCI (12).

PROMIS $^{\circledR}$ is a dynamic and extensive set of self-report measures to evaluate various aspects of health, functioning or QoL (18). PROMIS ${ }^{\circledR}$ consists of item banks extensively covering 3 core health domains (Physical, Mental and Social) and, separately, Generic Global Health. Item banks are a collection of items that each measure the same domain. From Item banks, single items are valid to be used alone (19).

$$
\rho \quad \delta \quad M \quad{ }^{\circledR} \text { questions was }
$$

made by a group of 7 volunteers with SCI by using the content validity indexing technique (CVI) (20). Only questions with questionnaire (12).

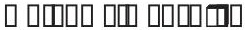

Participants were sent an invitation letter containing a questionnaire, and they provided answers either electronically or in

$$
\rho \rho \quad \delta \quad \delta \quad \delta \rho \quad \delta \quad \delta
$$

asked to self-indicate whether they were employed full time or part time, or if they did not work; multiple status options were

$$
\begin{array}{lllll}
\delta & \rho & \delta & \rho & \delta
\end{array}
$$

having worked for at least $1 \mathrm{~h}$ to earn a salary or entrepreneurial income during the survey week.

Of all the PROMIS ${ }^{\circledR}$ questions in the FinSCI questionnaire, PROMIS $^{\circledR}$ $\rho \delta$

from 3 different PROMIS ${ }^{\circledR}$ Social Health short forms were selected for this study to evaluate respondents' overall Physical, M $\delta \quad \quad M{ }^{\circledR}$ short forms described above were translated into Finnish (21).

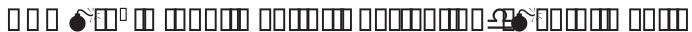

The PROMIS ${ }^{\circledR}$ Global Health survey is a generic 10-item measure for self-reported QoL and Social, Physical and Mental Health. Its measures are used in a general context to globally $\rho \quad \delta \quad \delta \quad \rho \quad \delta$ of PROMIS ${ }^{\circledR}$ Global Health has been shown to be reliable, pre$\delta \quad \rho \quad \delta \mathrm{M}$

in patient-reported outcome studies $(9,19)$.

The PROMIS ${ }^{\circledR}$ Global Health measure produces 2 scores: Physical Health (4 items on overall physical health, physical function, pain and fatigue) and Mental Health (4 items on QoL, mental health, satisfaction with social activities, and emotional problems) (19). Physical Health and Mental Health T-scores (range 20-80) can be calculated through an online scoring $\rho \quad \rho \delta \delta$ $\rho$ center.net/ac_scoringservice). The T-score distributions are standardized with a mean of 50 and a standard deviation (SD)
$\rho \quad \rho \quad \rho$ $\rho$
$\rho$ $\rho \delta$ $\rho$ standardized scores for Finland are unavailable, T-scores were calculated using the standard scores for the US population.
The scoring system of the PROMIS ${ }^{\circledR}$ Global Health allows each individual item to be examined separately to provide $\rho \quad M{ }^{\circledR}$ Global Health Scale

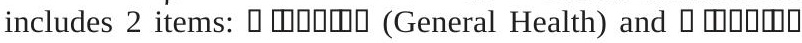
(Satisfaction with Social Roles). These items are uncalibrated, and it is not possible to generate T-scores from them; their raw response scores are recommended to be utilized for analyses (23).

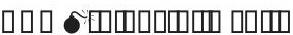

Social Health was measured by individually selected items from 3 PROMIS Social Health short Forms: (प) PROMIS Short $\rho$ $\delta$

(3 items), which assesses satisfaction with performing usual social roles and activities, including the ability to work (24);

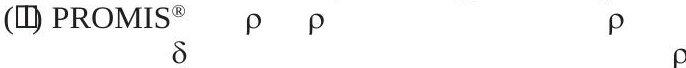
to perform usual and important work, including work at home (25); and (س) PROMIS ${ }^{\circledR}$ Item Bank v.1.0 - Satisfaction with $\rho$ which measures self-reported contentment with leisure interests and relationships with friends over the past 7 days (26). Three sum variables were formed from the raw scores of the 7 items above to measure Social Health. Conversion into T-scores could not be performed because fewer than 4 (or 50\%) items from Short Form Banks were selected (27).

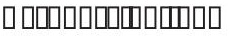

The quality of response options varied according to measurable variables. Physical and Mental Health response options for single questions varied measuring time, opinion, or quantity on a scale of 1-5. In Global Health, higher scores for responses in-

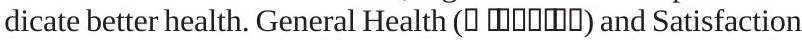
with Social Roles ( from "Poor" to "Excellent" (22). Pain was evaluated on a 0-10 scale $(0=$ No pain and $10=$ Worst pain imaginable). Recoding response scores from $0-10$ to $1-5$ was done automatically in the HealthMeasures Scoring Service (22). In Social Health questions, response options measuring time, opinion or quantity for single questions were given on a Likert scale of 1-5.

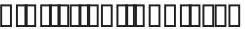

Descriptive statistics were used to describe sex, age, family relations, cause of injury, years since injury, and severity of injury of the participant sample groups. Group differences were tested

${ }^{2}$ test. Lesion characteristics were reported and analysed as recommended in the International Spinal Cord Injury Core dataset (version 2.0) (28).

The statistical tests used in the study were non-parametric tests, because data were not normally distributed. Sociodemographic data and SCI characteristics are presented as frequencies and percentages, means and standard deviations (SD), or medians and $25^{\text {th }}$ and $75^{\text {th }}$ percentiles (interquartile range; IQR).

Physical, Mental, General and Social Health were compared between employment status groups according to sex, age group, injury aetiology, time elapsed since injury and severity of SCI, using a Mann-Whitney $\mathrm{C}$ test.

For internal consistency of the PROMIS ${ }^{\circledR}$ Global Health, $\rho \quad \delta \quad \rho$ Physical Health (4 items) and Mental Health (4 items). Internal consistencies of the Social Health sum variables were also asses- 
sed by Cronbach's alpha, inter-item correlations and item-total $\rho p \quad \rho \quad \rho \delta$ and values as low as 0.60 may be acceptable for exploratory $\rho \rho$ $\delta \quad \rho \quad M \quad \rho$

$$
\rho \quad \delta
$$

$\rho \rho \quad \rho$

Binary logistic regression analysis, including estimated odds $\rho$

$$
\delta \quad \rho
$$

$$
\rho \quad \rho
$$

formed to identify the associations between the dependent variable (work participation) and each of the several demographic, injury-related and health-related independent variables. Both univariable and multivariable models were used. For binary logistic regression, because of the small number of cases in certain lesion groups when applying ISNCSCI injury severity plegia and tetraplegia.

$$
\rho \delta \delta \quad \rho \quad \rho-
$$

$$
\rho \quad \delta \rho \delta
$$

$\rho$ Q-values

$<0.05$. Statistical analyses were performed using SPSS version

$$
\rho \quad \rho \quad \rho \delta \quad \rho^{\mathrm{SM}} \text { was used }
$$
to produce T-score calculations for PROMIS ${ }^{\circledR}$ Global Health.

\section{RESULTS}

Of the 884 respondent participants in the survey, 452 working and individually determined working-aged persons were included in this study: 87 (19.2\%) were full-time employed, 33 (7.3\%) part-time employed, and 332 (73.5\%) were not working. The work-age not working group consisted of persons who were unemployed (4.5\%), students (4.2\%), people on disability pension

(81.6\%), on family leave ( $0.6 \%)$, on sick leave (2.4\%), on vocational training $(0.6 \%)$ or other reason $(3.6 \%)$.

There was no difference in work participation between the sexes. Family relations or having children were not related to work participation. The study sample was divided into 2 age groups by median age (54 years). The 20-53 age group was found to be more involved in work compared with those aged 54-74 years. Of working persons, $12.5 \%$ had tetraplegia, and $87.5 \%$ had paraplegia.

The reliability analysis for internal consistency of the PROMIS ${ }^{\circledR}$ Global Health demonstrated good reliability $\rho \mathrm{M} \quad \rho \quad \delta \quad-$ tionable reliability for Physical Health; Cronbach's

ability to carry out everyday physical activities question (Global06) lowered the internal consistency of Physical Health in this data (alpha if item deleted 0.690). Social Health sum variables demonstrated high reliability, whereas Cronbach's alphas were in Satisfaction with Participation in Discretionary Social

$\delta$

\section{$\delta$}

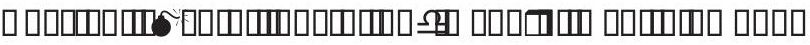

\begin{tabular}{|c|c|c|c|c|c|c|c|}
\hline \multirow{4}{*}{$n=452$} & \multirow[b]{2}{*}{ Mean (SD; Cl) } & \multicolumn{2}{|c|}{ Physical Health (T-Score) 0.616} & \multirow[b]{4}{*}{$\begin{array}{l}\text { Differences } \\
\text { btw labour } \\
\text { status groups } \\
\text { (p) }\end{array}$} & \multicolumn{2}{|c|}{ Mental Health (T-Score) 0.893} & \multirow[b]{4}{*}{$\begin{array}{l}\text { Differences } \\
\text { btw labour } \\
\text { status groups } \\
\text { (p) }\end{array}$} \\
\hline & & \multicolumn{2}{|c|}{$39.9(7.7 ; 39.2-40.7)$} & & \multicolumn{2}{|c|}{$43.1(9.2 ; 42.2-43.9)$} & \\
\hline & \multirow[b]{2}{*}{$\begin{array}{l}\text { Mean }(\mathrm{SD} ; \mathrm{Cl}) \\
\text { Differences btw } \\
\text { groups }(p)\end{array}$} & $\begin{array}{l}\text { Employed } \\
\text { Median (IQR) }\end{array}$ & $\begin{array}{l}\text { Work aged not at } \\
\text { work } \\
\text { Median (IQR) }\end{array}$ & & $\begin{array}{l}\text { Employed } \\
\text { Median (IQR) }\end{array}$ & $\begin{array}{l}\text { Work aged not at } \\
\text { work } \\
\text { Median (IQR) }\end{array}$ & \\
\hline & & $44.3(39.8-49.2)$ & $\begin{array}{l}38.1(33.0-42.1) \\
0.001^{\mathrm{a}}\end{array}$ & & $46.8(41.1-53.1)$ & $\begin{array}{l}41.5(35.5-46.6) \\
.001^{a}\end{array}$ & \\
\hline \multirow[t]{2}{*}{ Gender } & Male & $44.1(39.6-48.8)$ & $38.1(32.5-41.8)$ & $p<0.001^{a}$ & $46.4(38.9-53.1)$ & $40.9(35.5-46.2)$ & $p<0.001^{a}$ \\
\hline & Female & $46.1(40.4-50.8)$ & $37.9(33.2-42.8)$ & $\mathrm{p}<0.001^{\mathrm{a}}$ & $49.6(43.0-54.6)$ & $43.3(36.2-47.5)$ & $\mathrm{p}<0.001^{\mathrm{a}}$ \\
\hline \multirow[t]{2}{*}{ Age group } & 20-53 years & $44.3(40.7-48.9)$ & $39.8(34.2-44.3)$ & $\mathrm{p}<0.001^{\mathrm{a}}$ & 46.6. (41.5-53.1) & $42.4(36.0-50.4)$ & $0.006^{\mathrm{a}}$ \\
\hline & $54-74$ years & $43.8(39.6-50.7)$ & $36.9(32.5-40.7)$ & $\mathrm{p}<0.001^{\mathrm{a}}$ & $47.3(40.9-53.1)$ & $41.5(35.5-44.8)$ & $\mathrm{p}<0.001^{\mathrm{a}}$ \\
\hline \multirow[t]{2}{*}{ Cause of the injury } & Traumatic & $44.3(39.8-49.2)$ & $39.0(34.2-43.0)$ & $\mathrm{p}<0.001^{\mathrm{a}}$ & $47.5(43.3-53.1)$ & $43.0(36.2-48.3)$ & $\mathrm{p}<0.001^{\mathrm{a}}$ \\
\hline & Non-traumatic & $43.8(39.6-49.1)$ & $37.1(32.1-41.3)$ & $\mathrm{p}<0.001^{\mathrm{a}}$ & $45.7(38.5-53.5)$ & $40.6(34.2-45.2)$ & $p<0.001^{a}$ \\
\hline \multirow[t]{3}{*}{ Time since injury } & $1-5$ years & $44.3(40.1-49.9)$ & $37.3(32.1-41.1)$ & $\mathrm{p}<0.001^{\mathrm{a}}$ & $48.2(43.3-53.1)$ & $38.9(35.5-43.6)$ & $p<0.001^{a}$ \\
\hline & $6-10$ years & $44.3(41.5-49.2)$ & $37.2(32.7-41.7)$ & $\mathrm{p}<0.001^{\mathrm{a}}$ & $46.6(40.9-53.1)$ & $41.8(35.6-46.6)$ & $0.016^{a}$ \\
\hline & 16 years & $42.1(39.6-54.0)$ & $39.2(33.0-44.3)$ & $0.010^{\mathrm{a}}$ & $51.1(40.9-58.1)$ & $44.8(37.2-51.3)$ & $0.093^{a}$ \\
\hline \multirow[t]{4}{*}{$\begin{array}{l}\text { Severity of spinal } \\
\text { cord injury }\end{array}$} & $\begin{array}{l}\text { AlS C1-C4 A, } \\
\mathrm{B}, \mathrm{C}\end{array}$ & $47.4(41.1-49.4)$ & 35.1 (31.4-41.9) & $0.001^{a}$ & $50.7(42.7-57.7)$ & $43.3(36.6-51.8)$ & $0.078^{a}$ \\
\hline & $\begin{array}{l}\text { AIS C5-C8 A, } \\
B, C\end{array}$ & $40.4(39.0-46.7)$ & $39.4(33.4-42.7)$ & $0.288^{a}$ & $54.6(43.3-58.1)$ & $44.1(38.1-47.1)$ & $0.058^{a}$ \\
\hline & AIS T1-S5 A, B, C & $42.8(40.6-49.2)$ & $39.6(34.2-44.3)$ & $0.003^{a}$ & $45.6(38.5-54.4)$ & $43.3(36.2-50.4)$ & $0.270^{\mathrm{a}}$ \\
\hline & $\begin{array}{l}\text { AIS D in all } \\
\text { neurological } \\
\text { levels }\end{array}$ & $44.3(39.6-50.3)$ & $37.7(33.0-41.4)$ & $0.001^{a}$ & $46.6(41.5-53.1)$ & $40.2(35.5-44.5)$ & $0.001^{a}$ \\
\hline
\end{tabular}

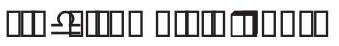

The employed group had better Physical, Mental (Table II) and General Health (Table IV), and, in addition, they

Table II. Physical and Mental Health of the participants ${ }^{\mathrm{b}}$ working and not at work in the Finnish Spinal Cord Injury population stratified for demographic and $\mathrm{SCl}$-related characteristics $(n=452)$

Cronbach's alpha. ${ }^{\mathrm{b}}$ Retired people are not included in a sample. Abnormal distribution in all groups: T-scores are expressed as Medians with Interquartile Range. P-values for group differences were obtained using: ${ }^{a}$ Mann-Whitney U Test. SCI: Spinal Cord Injury; AIS: ASIA Impairment Scale. 


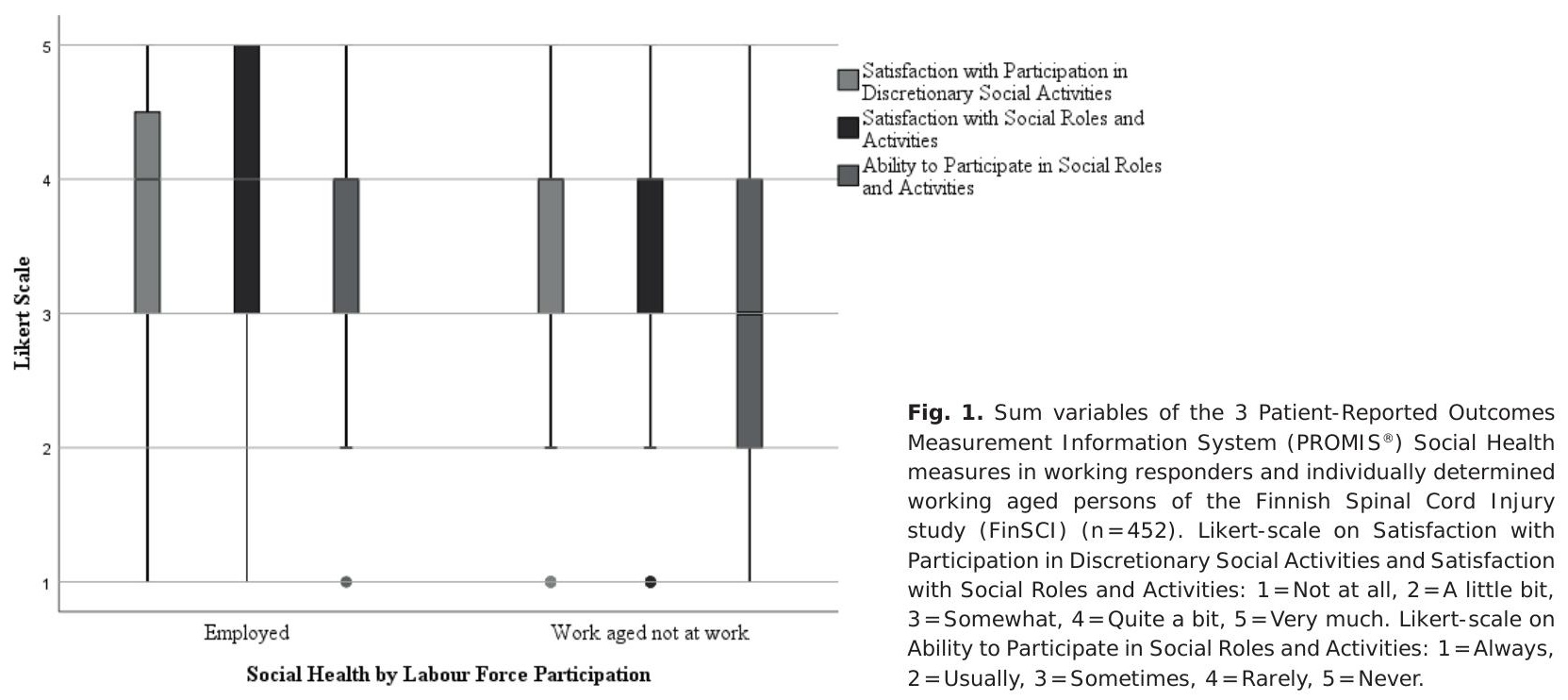

expressed overall better Social Health (Table III/Fig. 1) and higher Satisfaction with Social Roles compared with work-aged persons not working (Table V).

When comparing employed and work aged not working groups, the employed group had better Physical Health in all other groups except in a group where persons were injured 11-15 years previously and $\delta$

$$
\rho \rho
$$

These above-mentioned groups did not have statisti$\delta \rho$ they were at work or not.

Employed persons expressed higher Mental health compared with the work aged not working group in

$\begin{array}{cccccc}\rho & \rho & & \rho & & \\ \rho & \delta & & \rho & \rho & \rho \\ & & & & \delta & \end{array}$

Table III. Social Health of the participants ${ }^{b}$ working and not at work in the Finnish Spinal Cord Injury population stratified for demograph ic and $\mathrm{SCl}$-related characteristics $(n=452)$

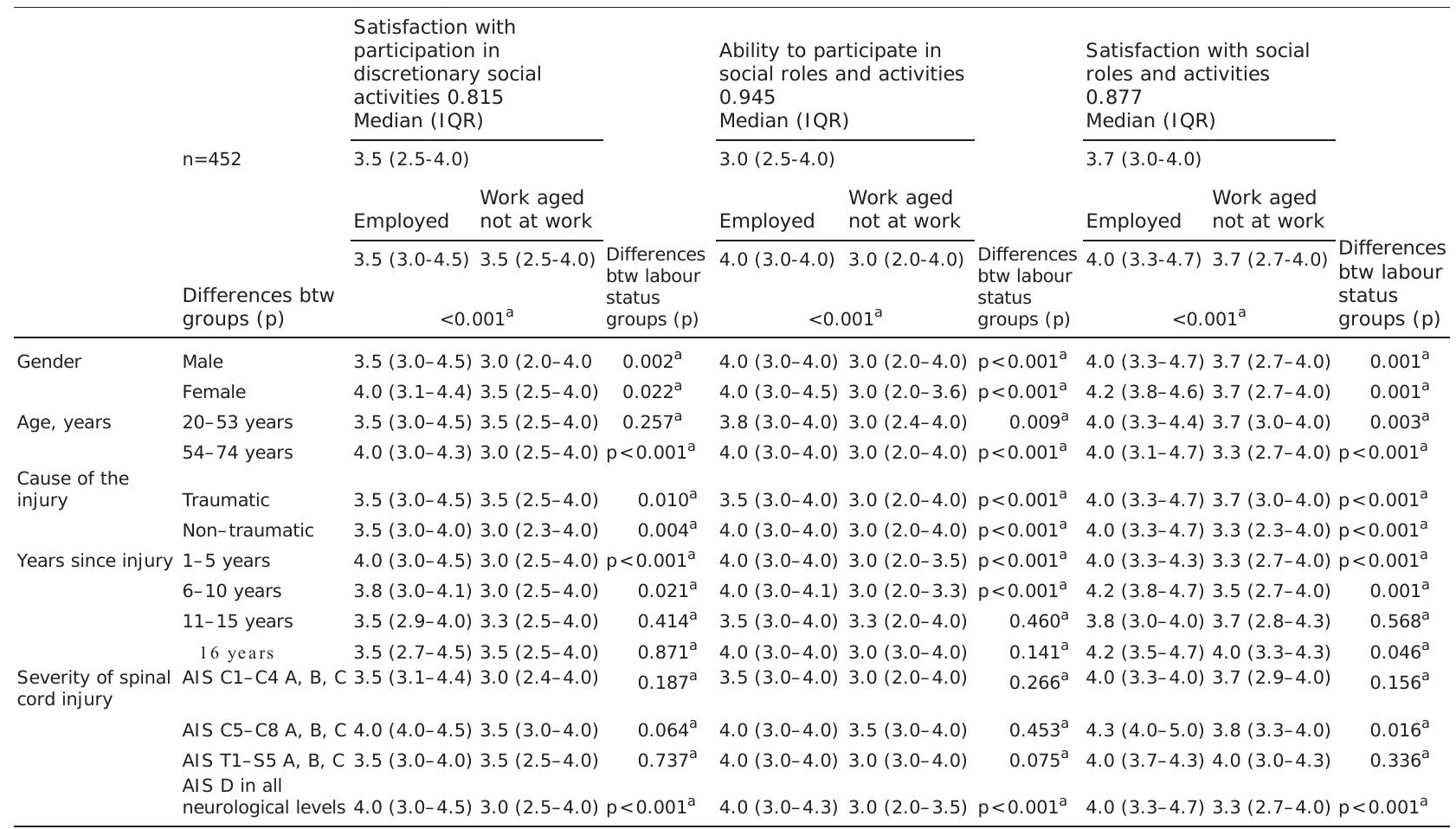

Cronbach's alpha. ${ }^{a}$ Mann-Whitney U-test, ${ }^{b}$ Retired people are not included in a sample. SCI: Spinal Cord Injury; AIS: ASIA Impairment Scale. 
Table IV. General Health of the participants ${ }^{b}$ working and not at work in the Fin nish Spinal Cord Injury Population stratified for de m ographic and $\mathrm{SCl}$-related characteristics $(n=452)$

\begin{tabular}{|c|c|c|c|c|c|c|c|c|c|}
\hline & & & $\mathrm{n}$ & $\begin{array}{l}\text { Poor (1) } \\
\text { n (\%) }\end{array}$ & $\begin{array}{l}\text { Fair (2) } \\
\text { n (\%) }\end{array}$ & $\begin{array}{l}\text { Good (3) } \\
\mathrm{n}(\%)\end{array}$ & $\begin{array}{l}\text { Very good (4) } \\
\mathrm{n}(\%)\end{array}$ & $\begin{array}{l}\text { Excellent (5) } \\
\mathrm{n}(\%)\end{array}$ & p-value \\
\hline & & & 452 & $33(7.3)$ & $186(41.2)$ & $156(34.6)$ & $61(13.5)$ & $15(3.3)$ & \\
\hline \multirow[t]{2}{*}{ Labour force participation } & Employed & & 120 & $6(5.0)$ & $23(19.2)$ & $49(40.8)$ & $33(27.5)$ & $9(7.5)$ & \multirow{2}{*}{$<0.001^{a}$} \\
\hline & Work aged not at work & & 331 & $27(8.2)$ & $163(49.2)$ & $107(32.3)$ & $28(8.5)$ & $6(1.8)$ & \\
\hline \multirow[t]{3}{*}{ Gender } & Employed & Male & 86 & $5(5.8)$ & $20(23.3)$ & $38(44.2)$ & $17(19.8)$ & $6(5.0)$ & \multirow{2}{*}{$<0.001^{a}$} \\
\hline & Work aged not at work & Male & 225 & $23(10.2)$ & $109(48.4)$ & $72(32.0)$ & $16(7.1)$ & $5(2.2)$ & \\
\hline & Employed & Female & 34 & $5(3.6)$ & $57(40.7)$ & $46(32.9)$ & $28(20)$ & $4(2.9)$ & $<0.001^{\mathrm{a}}$ \\
\hline \multirow[t]{4}{*}{ Age, years } & Employed & 20-53 years & 73 & $5(6.8)$ & $11(15.1)$ & $32(43.8)$ & $17(23.3)$ & $8(11.0)$ & \multirow{2}{*}{$<0.001^{a}$} \\
\hline & Work aged not at work & $20-53$ years & 150 & $7(4.7)$ & $59(39.3)$ & $58(38.7)$ & $21(14.0)$ & $5(3.3)$ & \\
\hline & Employed & $54-74$ years & 47 & $1(2.1)$ & $12(25.5)$ & $17(36.2)$ & $16(34.0)$ & $1(2.1)$ & \multirow{2}{*}{$<0.001^{a}$} \\
\hline & Work aged not at work & $54-74$ years & 181 & $20(11.0)$ & $104(57.5)$ & $49(27.1)$ & $7(3.9)$ & $1(0.6)$ & \\
\hline \multirow[t]{4}{*}{ Cause of the Injury } & Employed & Traumatic & 70 & $4(5.7)$ & $12(17.1)$ & $26(37.1)$ & $20(28.6)$ & $8(11.4)$ & \multirow{2}{*}{$<0.001^{a}$} \\
\hline & Work aged not work & Traumatic & 199 & $13(6.5)$ & $90(45.2)$ & $70(35.2)$ & $20(10.1)$ & $6(3.0)$ & \\
\hline & Employed & Non-traumatic & 50 & $2(4.0)$ & $11(22.0)$ & $23(46.0)$ & $13(26.0)$ & $1(2.0)$ & \multirow{2}{*}{$<0.001^{a}$} \\
\hline & Work aged not work & Non-traumatic & 132 & $14(10.6)$ & $73(55.3)$ & $37(28.0)$ & $8(6.1)$ & $0(0.0)$ & \\
\hline \multirow{6}{*}{ Time since Injury } & Employed & $6-10$ years & 31 & $1(3.2)$ & $6(19.4)$ & $14(45.2)$ & $8(25.8)$ & $2(6.5)$ & \multirow{2}{*}{$<0.001^{a}$} \\
\hline & Work aged not at work & $6-10$ years & 76 & $5(6.6)$ & $39(51.3)$ & $25(32.9)$ & $6(7.9)$ & $1(1.3)$ & \\
\hline & Employed & $11-15$ years & 18 & $3(16.7)$ & $3(16.7)$ & $5(27.8)$ & $6(33.3)$ & $1(5.6)$ & \multirow{2}{*}{$0.215^{\mathrm{a}}$} \\
\hline & Work aged not at work & $11-15$ years & 59 & $5(8.5)$ & $24(40.7)$ & $20(33.9)$ & $8(13.6)$ & $2(3.4)$ & \\
\hline & Employed & 16 years & 26 & $1(3.8)$ & $5(19.2)$ & $9(34.6)$ & $8(30.8)$ & $3(11.5)$ & \\
\hline & Work aged not at work & 16 years & 73 & $2(2.7)$ & $30(41.1)$ & $29(39.7)$ & $10(13.7)$ & $2(2.7)$ & $0.012^{a}$ \\
\hline \multirow[t]{8}{*}{ Severity of spinal cord injury } & Employed & AlS C1-C4 A, B, C & 8 & $0(0.0)$ & $1(12.5)$ & $3(37.5)$ & $3(37.5)$ & $1(12.5)$ & \multirow{2}{*}{$0.030^{\circ}$} \\
\hline & Work aged not at work & AlS C1-C4 A, B, C & 44 & $3(6.8)$ & $17(38.6)$ & $16(36.4)$ & $7(15.9)$ & $1(2.3)$ & \\
\hline & Employed & AlS C5-C8 A, B, C & 7 & $1(14.3)$ & $0(0.0)$ & $3(42.9)$ & $3(42.9)$ & $0(0.0)$ & \multirow[b]{2}{*}{$0.218^{\circ}$} \\
\hline & Work aged not at work & AIS C5-C8 A, B, C & 24 & $2(8.3)$ & $9(37.5)$ & $8(33.3)$ & $4(16.7)$ & $1(4.2)$ & \\
\hline & Employed & AlS T1-S5 A, B, C & 29 & $1(3.4)$ & $5(17.2)$ & $11(37.9)$ & $8(27.6)$ & $4(13.8)$ & \multirow{2}{*}{$0.004^{\mathrm{a}}$} \\
\hline & Work aged not at work & AIS T1-S5 A, B, C & 82 & $2(2.4)$ & $34(41.5)$ & $33(40.2)$ & $1(13.4)$ & $2(2.4)$ & \\
\hline & Employed & AIS D in all neurological levels & 76 & $4(5.3)$ & $17(22.4)$ & $32(42.1)$ & $19(25.0)$ & $4(5.3)$ & \multirow{2}{*}{$<0.001^{a}$} \\
\hline & Work aged not at work & AIS D in all neurological levels & 181 & $20(11.0)$ & $103(56.9)$ & $50(27.6)$ & $6(3.3)$ & $2(1.1)$ & \\
\hline
\end{tabular}

${ }^{a}$ Mann-Whitney U-test. ${ }^{b}$ Retired people are not included in a sample. SCI: Spinal Cord Injury; AIS: ASIA Impairment Scale.

General health between employed and not working groups was better in all employed groups, except for persons 11-15 years since injury and SCI severity $\rho$

Social Health was assessed between employed and not working groups according to 4 variables (Fig. 1, Table III and Table V). Employed persons expressed higher satisfaction with participation in discretionary social activities compared with the work aged not working group in all other groups except in the younger

$$
\begin{array}{lllllll}
\delta & \rho & \rho & & \delta & \rho & \rho \\
& \rho & \rho & \rho & &
\end{array}
$$

to participate in social roles and activities was higher in all other employed groups compared with work aged not working groups, except for persons 11-15

$$
\begin{array}{llllll}
\delta_{\delta} \rho & \rho & \delta & & \rho \\
& & & \rho &
\end{array}
$$

tion with social roles and activities showed that the

$$
\begin{array}{llll}
\delta & \rho & \rho & \rho
\end{array}
$$

compared with the work aged not working group in all other groups, except persons 11-15 years since injury

$$
\delta
$$$$
\rho \rho
$$

The single question about Satisfaction with Social

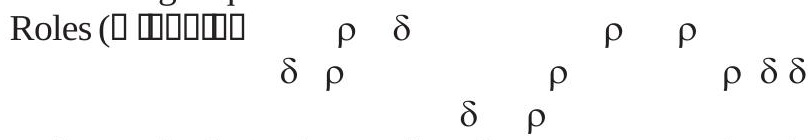
with social roles in the employed group compared with the work aged not working group (Table V).

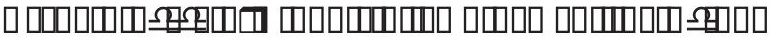

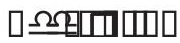

Logistic regression was performed to additionally explore the effects of demographic- and injury-related factors, together with different aspects of perceived health on the likelihood of work participation. The logistic regression

$$
\begin{array}{llllllllll}
\delta & \rho & \rho & \rho & \delta & \rho & \rho & \delta & \delta & \rho-
\end{array}
$$
ables to assess crude odds ratios (OR) for work participation. In univariable models, age, Physical Health, Mental Health, and all Social Health measures were associated with the likelihood of work participation (Table VI).

Three multivariable logistic regression models were constructed: (प) demographic and injury-related comparison; (प) adding Physical and Mental Health $\rho \quad \delta \quad \delta \quad$ 而) adding Social Health to the second model. Hosmer and Lemeshow's tests $\begin{array}{llll}\delta & \delta & \delta & \delta\end{array}$ 
Table V. Satisfaction with Social Roles (Global09) of the participants ${ }^{b}$ working and not at work in the Finnish Spinal Cord Injury Population stratified for demographic and SCI-related characteristics $(n=452)$

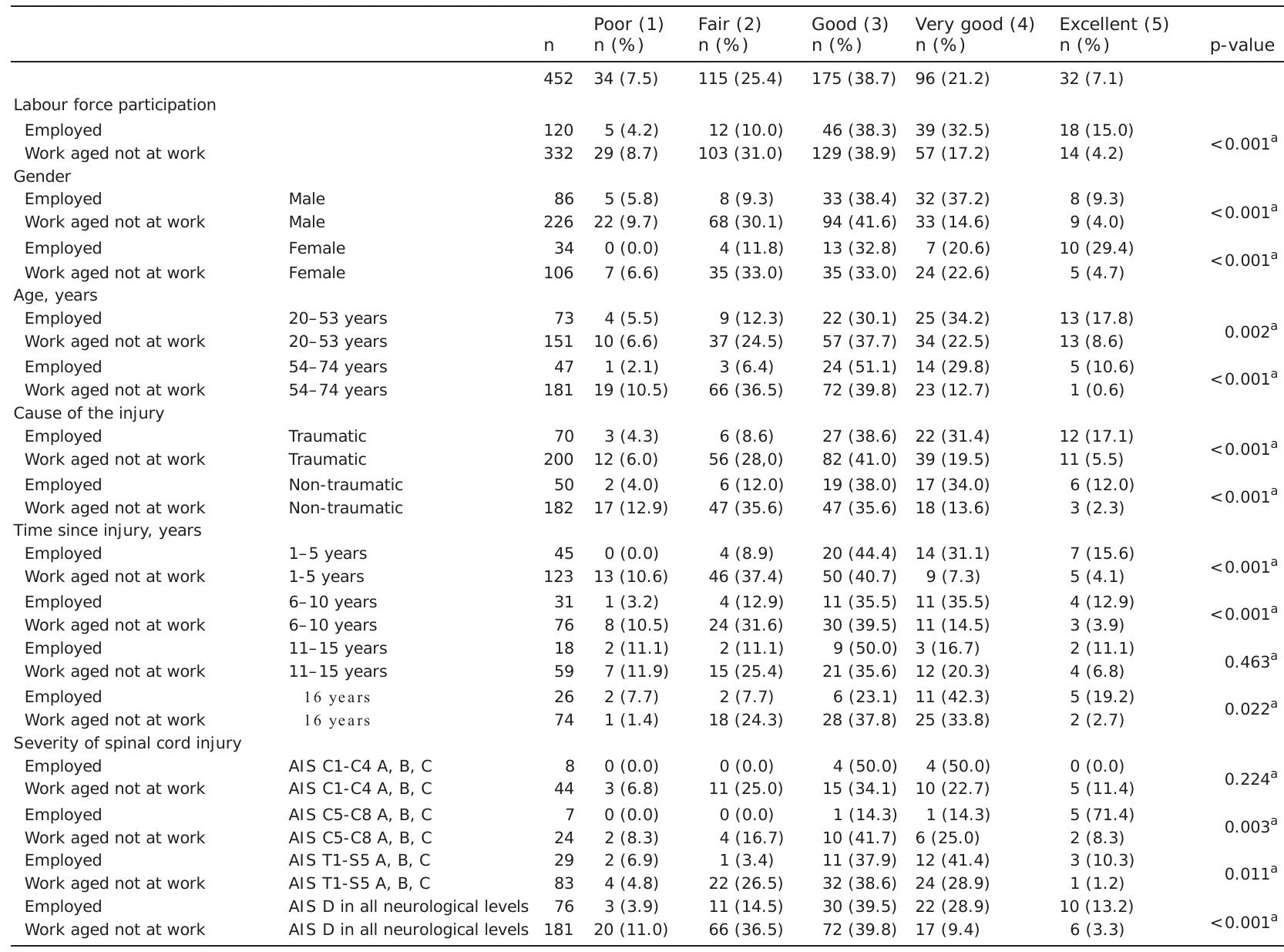

${ }^{\mathrm{a}}$ Mann-Whitney U-test. ${ }^{\mathrm{b}}$ Retired people are not included in a sample. SCI: Spinal Cord Injury; AIS: ASIA Impairment Scale.

Table VI. Logistic regression for demographic, $\mathrm{SCl}$-characteristic and health-related factors associated with work participation in the Finnish Spinal Cord Injury Population $(n=452)$

\begin{tabular}{|c|c|c|c|c|c|c|c|c|c|c|c|c|c|}
\hline \multirow{2}{*}{\multicolumn{2}{|c|}{ Control Variable }} & \multicolumn{3}{|c|}{ Crude OR } & \multicolumn{3}{|c|}{$\begin{array}{l}\left(\text { Nagelkerkes } R^{2}=0.046\right. \\
p=0.016, n=452)\end{array}$} & \multicolumn{3}{|c|}{$\begin{array}{l}\text { Including physical } \\
\text { and mental health } \\
\text { ( Nagelkerkes } R^{2}=0.208 \text {, } \\
p=0.693, n=452)\end{array}$} & \multicolumn{2}{|c|}{$\begin{array}{l}\text { Including } \\
\text { social health } \\
\text { (Nagelkerkes } \\
\mathrm{R}^{2}=0.209 \\
\mathrm{p}=0.394, \mathrm{n}=430 \text { ) }\end{array}$} & \multirow[b]{2}{*}{$p$} \\
\hline & & $\begin{array}{l}\text { Odds } \\
\text { Ratio }\end{array}$ & $(95 \% \mathrm{Cl})$ & $\mathrm{p}$ & $\begin{array}{l}\text { Odds } \\
\text { Ratio }\end{array}$ & $(95 \% \mathrm{Cl})$ & $p$ & $\begin{array}{l}\text { Odds } \\
\text { Ratio }\end{array}$ & $(95 \% \mathrm{Cl})$ & $\mathrm{p}$ & $\begin{array}{l}\text { Odds } \\
\text { Ratio }\end{array}$ & $(95 \% \mathrm{Cl})$ & \\
\hline Age, years & & 0.976 & $0.959-0.994$ & 0.010 & 0.971 & $0.952-0.990$ & 0.003 & 0.988 & 0.967- 1.009 & 0.246 & 0.990 & $0.968-1.012$ & 0.365 \\
\hline Cause of the Injury & [Ref:Traumatic] & 0.924 & $0.605-1.412$ & 0.715 & 0.857 & $0.538-1.368$ & 0.519 & 0.735 & $0.444-1.215$ & 0.229 & 0.786 & $0.469-1.318$ & 0.361 \\
\hline Time since Injury & [Ref: $\quad 16$ years ] & & & & & & & & & & & & \\
\hline $1-5$ years & & 1.041 & $0.593-1.827$ & 0.888 & 0.821 & $0.447-1.507$ & 0.524 & 1.013 & $0.520-1.971$ & 0.970 & 1.220 & $0.613-2.429$ & 0.571 \\
\hline $6-10$ years & & 1.161 & $0.630-2.140$ & 0.633 & 0.879 & $0.460-1.681$ & 0.697 & 1.132 & $0.559-2.289$ & 0.731 & 1.357 & $0.650-2.832$ & 0.416 \\
\hline $11-15$ years & & 0.868 & $0.435-1.734$ & 0.689 & 0.718 & $0.351-1.469$ & 0.364 & 0.893 & $0.416-1.917$ & 0.772 & 0.996 & $0.445-2.177$ & 0.991 \\
\hline Severity of $\mathrm{SCl}$ & [Ref: Paraplegia] & & & & & & & & & & & & \\
\hline Tetraplegia & & 0.555 & $0.303-1.014$ & 0.055 & 0.483 & $0.255-0.915$ & 0.026 & 0.597 & $0.297-1.200$ & 0.147 & 0.722 & $0.350-1.490$ & 0.379 \\
\hline Mental Health & & 1.065 & $1.039-1.091$ & $<0.001$ & & & & 1.012 & $0.978-1.047$ & 0.492 & 1.007 & $0.967-1.050$ & 0.722 \\
\hline Satisfaction with $\mathrm{P}$ & Participation & 1.483 & $1.204-1.828$ & $<0.001$ & & & & & & & 0.785 & 0.561-1.099 & 0.159 \\
\hline Satisfaction with & Social Roles & 1.830 & $1.425-2.349$ & $<0.001$ & & & & & & & 1.002 & $0.654-1.535$ & 0.993 \\
\hline Ability to participa & ate in Social Roles & 1.944 & $1.550-2.439$ & $<0.001$ & & & & & & & 1.403 & $1.022-1.927$ & 0.036 \\
\hline
\end{tabular}

${ }^{1}$ Hosmer and Lemeshow Test p-value. SCI: Spinal Cord Injury; CI: Confidence Interval. 


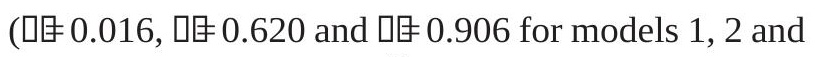
$\rho$

$\delta \quad \rho$

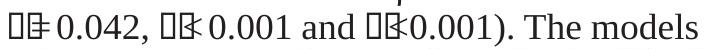
explained $4.6 \%, 21.4 \%$ and $21.7 \%$ (Nagelkerke $\mathrm{Q}^{2}$ ) of the variance of work participation and correctly clas$\delta$ $\delta$

Logistic regression shows that the odds of being employed decreased with increasing age (OR 0.976, 95\% CI 0.959-0.994). The OR suggests that males were more likely to participate in work compared with $\rho$ $\delta$ $\rho$ (paraplegia) and younger age were associated with an increased likelihood of work participation. When different aspects of health were evaluated, Physical Health was found to be the strongest indicator assessing the likelihood of being at work. It remained statistically

$\delta \quad \delta \quad{ }^{\rho} \quad \delta$

work participation. The post-regression analysis for Physical Health's 4 items revealed that Physical function and pain contribute to the statistical importance of Physical Health in assessing the likelihood of work participation.

\section{DISCUSSION}

$\delta \quad \rho \quad \rho \quad \rho \quad \rho-$ tional study of the Finnish SCI population (FinSCI), this study found that the overall level of employment was $26.5 \%$ among persons in this study population, a value that is clearly lower than the overall level of employment $(68.9 \%)$ in the general Finnish population aged 20-69 years (31). The current study broadly covered all aspects of health simultaneously, and it was observed that employed persons with SCI expressed better Physical, Mental, Social and General Health compared with the work-aged not working group. In particular, Physical Health (especially Pain and Physical function)

$\delta \quad \rho \quad \rho \quad \delta$

be the strongest indicators assessing the likelihood of being at work. Individuals who were less severely impaired (paraplegia) and at a younger age were associated with an increased likelihood of work participation. The current study showed that there are no differences in mental and social health in terms of employment status

$\rho \rho$

\section{$\delta$}

$$
\rho \quad \delta \quad \rho \quad \rho \quad \rho
$$

The use of PROMIS ${ }^{\circledR}$ Global Health to explain par-

$$
\rho \quad \rho \delta \delta \quad \rho \delta
$$

of other studies in terms of health-related factors. Poor health has been shown to be associated with a $59 \%$ $(\mathrm{OR}=0.41$; 95\% CI $0.22-0.76)$ reduction in having paid employment (32). Two studies have found that a greater number of depressive symptoms are correlated $\delta$ $\delta \rho$

$7-12 \%$ in the odds of being employed $(33,34)$.

Very few studies have been carried out on self-rated health in persons with SCI. Previous research evidence indicates that, although persons with SCI experience

$$
\rho \rho \delta \rho
$$

many perceive their health as good (3). Physical ability is an important factor associated with self-rated health for persons with SCI, but the strength of the relationship depends on the level of injury (paraplegia vs tetraplegia) (35). One's ability to perform activities that are most meaningful to carrying out one's roles seem to shape self-rated health $(3,35)$. The ability to perform activities of daily living may be an even more accurate predictor of work participation than is healthrelated impairments (36).

Previous studies of work participation among per$\delta$

personal characteristics increase the likelihood of employment post-SCI, including being male; younger at injury; having a longer duration of injury (20-30 years); being less severely injured; and having a higher level of independence (including wheelchair skills) (2, 36, 37). Individuals with complete and incomplete tetraplegia (OR 0.46; OR 0.59, respectively) have been shown to have a lower likelihood of having paid work (35). Similarly, higher and more severe injury (i.e. tetraplegia and complete injury) was found to negatively

\section{$\delta$}

PROMIS $^{\circledR}$ Physical Health includes 4 items on overall physical health, physical function, pain, and fatigue. Pain as a single item is recognized in multiple previous studies as a barrier to performing paid work $(10,11,36,38,39)$, but in individual studies, there was

$$
\rho
$$

and work participation (37). Pain and fatigue have been found to independently associate with depression, but only pain has been associated with physical functioning (38). Physical functioning has been found to decline with increasing age, as well as with higher level of injury (38, 39). Physical Health's 2 most important interconnected items, physical function and pain, are found to affect work participation when including increasing age (39).

Being older and having a higher age at injury have been shown to affect whether an individual is employed to increase with age (up to approximately 30 years of age) and is maintained up to 40 years, younger age at injury and longer duration of injury (up to 20 years post-injury) are better predictors of being employed than age alone. Due to a non-linear effect of age on employment market participation, it is likely that 
work participation may decrease with increasing age $\rho \quad \rho$

persons with SCI have shown less social activity and have reported a greater number of health problems. Pain has been shown to have a correlation between chronological age and employment. Individuals 50 years of age and older appear to be at a higher risk of experiencing pain, but pain also seems to lead to a decrease in the likelihood of employment (1).

Participating in more social roles has been found to $\rho$ middle-aged and older adults (40). Social support has been shown to favour employment (33). Employment has a high value for persons with SCI because it has been shown to contribute to the creation of personal and collective identity and social recognition, distract from impairment and pain, and facilitate interaction with other people (5).

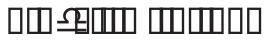

This study has several limitations. First, the crosssectional design precludes drawing causal interpretations about the observed relationships, and the

$$
\delta \quad \delta \quad \delta \quad \delta \quad \delta
$$

studies. Secondly, the sample of working and not-atwork persons with SCI was limited nationally and was relatively small. This study sample describes healthrelated factors at the national level in a high-income country and cannot be generalized to low-income countries. Half of all potential participants responded to the survey, introducing the potential for responder

$$
\rho p \delta \quad \delta \quad \delta
$$

was that the data comprise the majority of persons with SCI in Finland, because all 3 specialized SCI centres in Finland collaborated by providing access to patient registers for data collection.

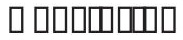

$$
\begin{array}{llllll}
\delta & \rho & \delta & \rho & \rho & \delta
\end{array}
$$

ment rates and health-related determinants of work participation among the SCI population in Finland. The results are in line with those of previous studies performed in different countries concerning determinants of work participation and low employment

\section{$\rho \quad \rho$}

PROMIS $^{\circledR}$

those of previous SCI studies of other legacy measu$\rho$

$$
\rho \quad \rho \quad \delta
$$

to Participate in Social Roles increase the chance of work participation. Particular attention should be paid to all domains of health-related factors in medical and vocational interventions aiming for sustainable work integration of persons with SCI.

\section{ACKNOWLEDGEMENTS}

The authors would like to thank all the individuals who participated and made this study possible. We also thank Kirsi Majamäki and Joonas Poutanen for saving questionnaires to electronic format.

\section{पिएधिए $\delta \quad \rho \delta$}

of People with Physical Disabilities (pr42105, 2017-2020), Oulu University Hospital (grant VTR K86709, 20.10.2017), the Department of Internal Medicine and Rehabilitation, Helsinki University Hospital (grants HUS/53/2017 §9, 9.6.2017, HUS/76/2018 § 11, 18.4.2018 and HUS/174/201 §1, 12.4.2019), and Validia Rehabilitation (grant HUS-VTR 9.3.2017).

The authors have no conĀicts of interest to declare.

\section{REFERENCES}

1. Krause JS, Bozard J L. Natural course of life changes after spinal cord injury: a 35-year longitudinal study. Spinal Cord 2012; 50: 227-231.

2. Escorpizo R, Smith EM, Finger ME, Miller WC. Work and employment following spinal cord injury. 2018 [cited 2021 May 15] Available from: https://scireproject.com/ wp-content/uploads/S6-Work-Employment-Chapter-_RE AC_MF_RE-MQ-Apr-11-2019.pdf.

3. Krahn GL, Suzuki R, Horner-Johnson W. Self-rated health in persons with spinal cord injury: relationship of secondary conditions, function and health status. Qual Life Res 2009; 18: 575-584.

4. Ottomanelli L, Lind L. Review of critical factors related to employment after spinal cord injury: implications for research and vocational services. J Spinal Cord Med 2009; 32: 503-531.

5. Leiulfsrud AS, Ruoranen K, Ostermann A, Reinhardt JD. The meaning of employment from the perspective of persons with spinal cord injuries in six European countries. Work (Reading, MA) 2016; 55: 133-144.

6. Post MW, Reinhardt JD, Avellanet M, Escorpizo R, Engkasan $J P$, Schwegler $U$, et al. Employment among people with spinal cord injury in 22 countries across the world: results from the International Spinal Cord Injury Community Survey. Arch Phys Med Rehabil 2020; 101: 2157-2166.

7. Eyh S, Nick E, Stirnimann D, Ehrat S, Miche F, Peter C, et al. Self-efficacy and self-esteem as predictors of participation in spinal cord injury - an ICF-based study. Spinal Cord 2012; 50: 699-706.

8. Tucker CA, Cieza A, Riley AW, Stucki G, Lai JS, Bedirhan Ustun $\mathrm{T}$, et al. Concept analysis of the Patient Reported Outcomes Measurement Information System (PROMIS ${ }^{\circledR}$ ) and the International Classification of Functioning, Disability and Health (ICF). Qual Life Res 2014; 23: 1677-1686.

9. Cella D, Riley W, Stone A, Rothrock N, Reeve B, Yount S, et al. The Patient-Reported Outcomes Measurement Information System (PROMIS) developed and tested its first wave of adult self-reported health outcome item banks: 2005-2008. J Clin Epidemiol 2010; 63: 1179-1194.

10. Lidal IB, Huynh TK, Biering-Sørensen F. Return to work following spinal cord injury: a review. Disabil Rehabil 2007; 29: 1341-1375.

11. Marti A, Reinhardt J D, Graf S, Escorpizo R, Post M. To work or not to work: labour market participation of people with spinal cord injury living in Switzerland. Spinal Cord 2012; 50: $521-526$.

12. Tallqvist $S$, Anttila $H$, Kallinen $M$, Koskinen $E$, Hämäläinen $H$, Kauppila A-M, et al. Health, functioning and accessibility among spinal cord injury population in Finland: Protocol for the FinSCl study. J Rehabil Med 2019; 51: 273-280.

13. Coulter A. Measuring what matters to patients. BMJ 2017 Feb [cited 2021 Apr 10]; 2017; 356: 816-816. Available 
from: https://www.bmj.com/content/356/bmj.j816.

14. Kirshblum SC, Burns SP, Biering-Sorensen F, Donovan W, Graves DE, J ha A, et al. International standards for neurological classification of spinal cord injury (Revised 2011). J Spinal Cord Med 2011; 34: 535-546.

15. Finnish Centre for Pensions. 2021 [cited 2021 Apr 11]. Available from: https://www.etk.fi/.

16. WHO. International Classification of Functioning, Disability and Health (ICF) Geneva: World Health Organization; 2001.

17. Gross-Hemmi MH, Post MW, Ehrmann C, Fekete C, Hasnan $\mathrm{N}$, Middleton JW, et al. Study Protocol of the International Spinal Cord I njury (InSCI) Community Survey. Am J Phys Med Rehabil 2017; 96: 23-34.

18. PROMIS (Patient-Reported Outcomes Measurement Information System) Slides Introducing HealthMeasures. [cited $2021 \mathrm{Apr} 11]$. Available from: https://www. healthmeasures. net/ explore-measurement-systems/promis/ intro-to-promis.

19. Hays RD, Bjorner J, Revicki DA, Spritzer K, Cella D. Development of physical and mental health summary scores from the Patient Reported Outcomes Measurement Information System (PROMIS) global items. Qual Life Res 2009; 18: 873-880.

20. Polit DF, Beck CT, Owen SV. Is the CVI an acceptable indicator of content validity? Appraisal and recommendations. Res Nurs Health 2007; 30: 459-467.

21. The national PROMIS-centre administered by Finnish Institute for health and welfare. PROMIS measures in Finnish. [Internet]. 2021 Apr 7 [Cited 2021 Apr 11] Available from: https://thl.fi/fi/web/toim intakyky/to im intakyvyn-arviointi/ kansallinen-promis-keskus\#Suomenkieliset\% 20PROMISmittarit_uusi.

22. PROMIS. Global Health. A brief guide to the PROMIS $\odot$ Global Health instruments. 2017 J un 3 [cited 2021 Apr 11]. Available from: https://www. healthmeasures.net/images/ PROMIS/manuals/PROMIS_Global_Scoring_Manual.pdf.

23. PROMIS. Resource Center. Analysis of PROMIS Global01 and 09 questions [Internet]. 2021 [Cited 2021 Apr 11]. Available from: https://www. healthmeasures. net/resource-center/user-community/forum/promis/263-analysis-ofpromis-global01-and-09-questions.

24. PROMIS. A brief guide to the PROMIS Satisfaction with Social Roles and Activities instruments. [Internet] 2014 Oct 22 [Cited 2021 Apr 11] Available from: http://www. healthmeasures. net/images/promis/manuals/PROMIS_ Satisfaction_with_Participation_in_Social_Roles_Scoring_Manual.pdf.

25. PROMIS. A briefguide to the PROMIS Profile instruments for adult respondent. [Internet] 2021 Apr 9 [Cited 2021 Apr 11] Available from: https://www. healthmeasures. net/images/PROMIS/manuals/Scoring_Manuals_/PROMIS_Adult_Profile_Scoring_Manual.pdf.

26. PROMIS. A brief guide to the PROMIS $®$ Satisfaction with Participation in Discretionary Social Activities v1.0 instruments. [Internet] 2018 March 22 [Cited 2021 Apr 11] Available from: https://www. healthmeasures.net/index. php?option $=$ com_instruments $\&$ view $=$ measure $\& i d=176 \&$ I temid=992.
27. PROMIS. Satisfaction with Participation in Discretionary Social Activities. A brief guide to the PROMIS Satisfaction with Participation in Discretionary Social Activities v1.0 instruments.. 2015 Aug 7 [cited 2021 Apr 11]. Available from: https://www. healthmeasures. net/images/promis/ manuals/PROMIS_Satisfaction_with_Participation_in_Discretionary_Social_Activities_Scoring_Manual.pdf.

28. Biering-Sorensen $\bar{F}$, DeVivo $M J$, Charlifue $S$, Chen $Y$, New PW, Noonan V, et al. International Spinal Cord Injury Core Data Set (version 2.0)-including standardization of reporting. Spinal Cord 2017; 55: 759-764.

29. Hair JF, Black WC, Babin BJ, Anderson RE. Multivariate data analysis: a global perspective. 7 th edn. Upper Saddle River, NJ: Prentice Hall; 2010.

30. George D, Mallery P. SPSS for Windows step by step: a simple guide and reference 18.0 update. 11th edn. Boston: Allyn \& Bacon; 2011.

31. Official Statistics of Finland: Labour Force Survey. 2021 May 25 [cited 2021 May 31]. Available from: https:// tilas tokeskus.fi/til/tyti/2021/04/tyti_2021_04_2021-0525_tie_001_en.html.

32. Botticello $A \bar{L}$, Chen $Y$, Tulsky DS. Geographic variation in participation for physically disabled adults: the contribution of area economic factors to employment after spinal cord injury. Soc Sci Med 2012; 75: 1505-1513.

33. Burns SM, Boyd BL, Hill J, Hough S. Psychosocial predictors of employment status among men living with spinal cord injury. Rehabil Psychol 2010; 55: 81-90.

34. Lin M-R, Hwang H-F, Yu W-Y, Chen C-Y. A prospective study of factors influencing return to work after traumatic spinal cord injury in Taiwan. Arch Phys Med Rehabil 2009; 90: 1716- 1722 .

35. Machacova K, Lysack C, Neufeld S. Self-rated health among persons with spinal cord injury: What is the role of physical ability? J Spinal Cord Med 2011; 34: 265-272.

36. Schwegler U, Fellinghauer CS, Trezzini B, Siegrist J. Factors associated with labour market participation of persons with traumatic SCl in Switzerland: analyzing the predictive power of social background, health, functional independence, and the environment. Spinal Cord 2020; 58: 411-422.

37. Roels EH, Reneman MF, Stolwijk-Swuste J, van LaakeGeelen CC, de Groot S, Aiaansen JJE, et al. Relationships between type of pain and work participation in people with long-standing spinal cord injury: results from a crosssectional study. Spinal Cord 2018; 56: 453-460.

38. Alschuler KN, Jensen MP, Sullivan-Singh SJ, Borson S, Smith AE, Molton IR. The association of age, pain, and fatigue with physical functioning and depressive symptoms in persons with spinal cord injury. J Spinal Cord Med 2013; 36: 483-491.

39. Marti A, Boes S, Lay V, Escorpizo R, Reuben Escorpizo PT, Trezzini $B$. The association between chronological age, age at injury and employment: Is there a mediating effect of secondary health conditions? Spinal Cord 2016; 54: 239-244.

40. Jetha A, Dumont FS, Noreau L, Leblond J. A Life course perspective to spinal cord injury and employment participation in Canada. Topics Spinal Cord Inj Rehabil 2014; 20: 310-320. 